\title{
Comparison of exercise tests and 24-hour ambulatory electrocardiographic monitoring in detection of ST-T changes
}

\author{
Eliana Wolf, Dan Tzivoni, and Shlomo Stern \\ From the Department of Physical Medicine and Rehabilitation, Medicine A, the Cardiology Service and the \\ Cardiac Station for Diagnosis and Follow-up, Hadassah University Hospital and Hebrew University-Hadassah \\ Medical School, ferusalem, Israel
}

Forty-seven subjects over the age of 40 years, with atypical praecordial symptoms and a normal resting electrocardiogram, were evaluated for early detection of ischaemic heart disease using the single two-step exercise test, the multistage bicycle ergometric test, and continuous 24-hour ambulatory electrocardiographic monitoring. In 40 of the 47 subjects the results of both the ergometric test and the 24-hour monitoring were similar; in I9 of them both tests were negative and in $2 I$ subjects ST-T changes were detected by both ergometry and 24-hour monitoring. A discrepancy between the two tests was found in only 7 subjects, 4 of whom showed ST-T changes on ergometry only and 3 on monitoring only. The single two-step test was positive in only II of the 47 patients and is regarded as much less sensitive than the other two methods.

$A$ good correlation was found between the multistage bicycle exercise test and 24-hour monitoring, and the combined application of both tests will increase the yield of detection of ST-T changes in patients with suspected ischaemic heart disease.

Patients suffering from atypical praecordial symptoms and who have normal resting electrocardiograms frequently present a diagnostic problem. Master's two-step exercise test was originally designed for detecting 'silent' coronary heart disease (Master, 1953). Subsequently, more sensitive ergometric bicycle or treadmill tests, which include recording of the electrocardiogram during exercise and in the postexercise period, have been widely used (König and Messin, 1970). Continuous 24hour electrocardiographic monitoring during unrestricted daily activities has recently been used as a new method for detecting transient arrhythmias (Gilson, Holter, and Glasscock, 1964; Corday et al., 1965; Stern et al., 1970), but insufficient information is at present available on the possibility of detecting ischaemic ST-T changes by this method.

In the present study the efficacy of 24-hour electrocardiographic monitoring in detecting ST-T changes was tested, by comparing the findings in

Received 25 April 1973.

1 Supported (in part) by a grant from the Joint Research Fund of the Hebrew University-Hadassah Medical School. patients with atypical praecordial symptoms with the results of the Master's two-step test and multistage bicycle ergometric examinations.

\section{Subjects and methods}

Studies were made on 30 men and 17 women over the age of 40 years. They all suffered from praecordial discomfort, and were referred for evaluation by general practitioners. In all cases the 12-lead electrocardiogram was normal at rest, and remained so in the erect position during hyperventilation and during the Valsalva manoeuvre. Master's single two-step test was performed in the usual way (Master and Rosenfeld, 1967), and the criteria for a positive test were restricted to ischaemictype ST depression of at least $\mathrm{I} \mathrm{mm}$ and/or $\mathrm{T}$ wave inversion.

The multistage exercise test was performed on the Elema bicycle ergometer, starting with a load of 150 kilopond metre per minute $(\mathrm{p} \mathrm{kpm} / \mathrm{min})$ at a speed of 50 revolutions per minute, and increasing it gradually by $150 \mathrm{p} \mathrm{kpm} / \mathrm{min}$ increments. Each exercise phase lasted 5 minutes after which a 5 -minute rest period followed. Lead $V_{5}$ only was recorded during the exercise, while leads I, II, aVL, aVF, and V5 were recorded every half a minute during the rest period. Blood pressure was measured before exercise and during the first, third, and 
fifth minutes of the rest period. The test was discontinued if the heart rate exceeded 150 beats a minute in patients aged 40 to 60 years, and 130 beats a minute in patients over the age of 60 , if the patients complained of chest pain or extreme fatigue, or if severe ST-T changes or arrhythmias occurred. ST depression of $\mathrm{I} \mathrm{mm}$ or more, occurring in any lead during or after exercise, or major $T$ wave inversion, served as criteria for a positive ergo- metric test. Patients who developed multiple ventricular premature beats or paroxysmal tachycardia in the absence of ST-T changes during the exercise or the recovery period were not included in this study.

All patients underwent continuous 24-hour electrocardiographic monitoring within a week of the ergometric test. The Holter ${ }^{1}$ recording system was used, with ${ }^{1}$ Avionics, Los Angeles, California.

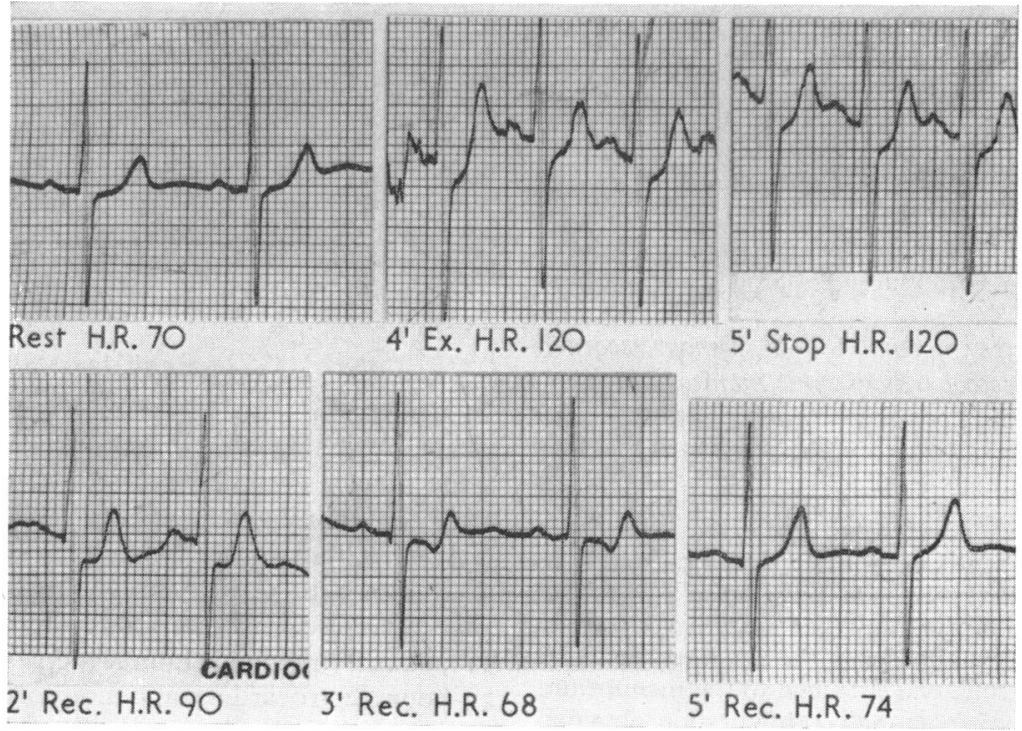

FIG. I Positive multistage exercise test. Ex.=exercise; Rec. $=$ recovery; H.R. =heart rate.

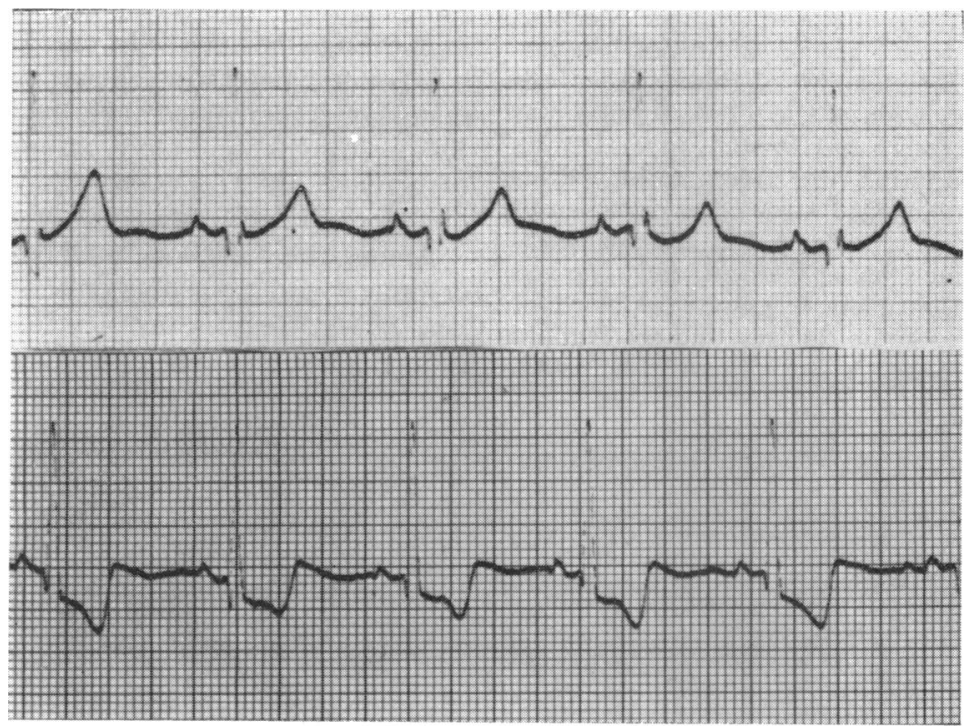

FIG. 2 Upper row: normal $S T-T$ segment recorded during 24-hour electrocardiographic monitoring. Lower row: pronounced $S T$ depression during the monitoring period, without signifcant change in heart rate. 


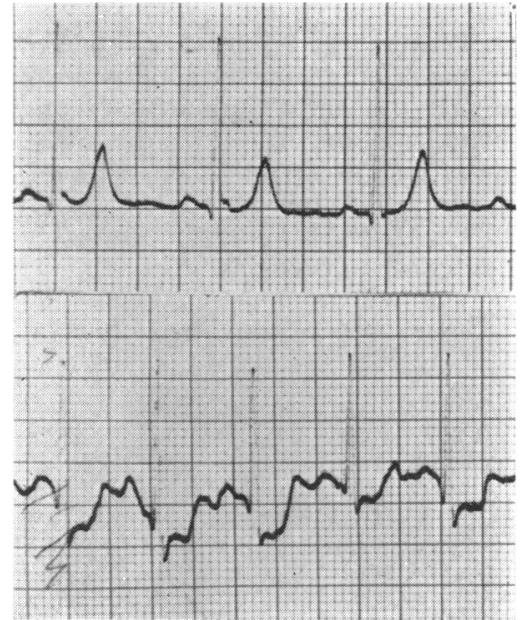

FIG. 3 Upper row: normal $S T-T$ segment recorded during 24-hour electrocardiographic monitoring. Lower row: $S T$ depression during effort, with tachycardia.

3 non-polarizable silver-silver chloride electrodes attached to the patient's chest. The exploring electrode was placed in the 5 th intercostal space at the $\mathrm{V}_{5}$ position of the conventional cardiograph; the 'negative' electrode was at the right sternal border in the 4th interspace and the 'ground' electrode was attached to the manubrium sterni. The electrocardiographic configuration obtained by this method resembled that seen in V5. Each patient was examined in the supine and the erect positions in order to avoid false interpretation due to postural changes. The patient was equipped with the Model E Electrocardiocorder which has an improved low frequency response. The reliability of this recorder was tested and the reproduction of the ST-T segment was found to be accurate (Stern and Tzivoni, 1972). During the 24 hours of monitoring, the patient continued his usual daily activities and was instructed to record accurately his praecordial symptoms, and details of physical effort undertaken, emotional excitement, and time and duration of sleep. The magnetic tapes were examined for possible electrocardiographic changes, and the findings were related to the patient's symptoms and activities.
TABLE 2 Results of multistage bicycle test and 24hour electrocardiographic monitoring in 47 patients

\begin{tabular}{llr} 
24-hour electrocardiographic monitoring & \multicolumn{2}{c}{ Multistage bicycle test } \\
\cline { 2 - 3 } & Positive & Negative \\
\hline Positive in 24 & 21 & 3 \\
Negative in 23 & 4 & 19 \\
\hline Total 47 & 25 & 22
\end{tabular}

An improved method of operating the Holter system was used (Tzivoni and Stern, 1972). Electrocardiographic monitoring was interpreted as positive if ST depression or elevation of at least $\mathrm{I} \mathrm{mm}$ and/or major $\mathrm{T}$ wave inversion were detected for several consecutive beats.

\section{Results}

In 19 patients no ST-T changes were detected either by the 24-hour monitoring or by the multistage bicycle ergometric or two-step exercise tests. In the remaining 28 patients at least one of these tests gave positive results, and the details are shown in Tables I to 5. Illustrative tracings are given in Fig. I-3. The Master two-step test was positive in II patients, the bicycle ergometric test in 25 , and 24-hour electrocardiograph monitoring in 24 patients (Tables I and 2). Twenty-one patients had positive findings on both ergometry and prolonged monitoring, though only Io of them had a positive two-step test (Table 3). The ST-T changes detected by the monitoring coincided with praecordial symptoms in 7 patients, whereas in the rest of them no symptomatology accompanied these findings. Though the ST-T changes were more prevalent during periods of activity, in I I patients they were noted also during periods of rest and even during sleep.

Among the 7 patients in whom the results by the ergometry and 24-hour monitoring tests differed, 4 had ST-T changes on bicycle exercise but were negative on electrocardiograph monitoring (Table 4)

TABLE I Summary of ST-T changes observed during 24-hour monitoring, multistage bicycle test, and single two-step test

\begin{tabular}{llllllll}
\hline & \multicolumn{9}{c}{ Positive } \\
\cline { 2 - 6 } & $\begin{array}{l}\text { ST depression } \\
\text { I mm or more }\end{array}$ & $\begin{array}{l}\text { ST elevation } \\
\text { I mm or more }\end{array}$ & $\begin{array}{l}T \text { wave } \\
\text { inversion }\end{array}$ & $\begin{array}{l}\text { Both } \\
\text { ST and } T \\
\text { change }\end{array}$ & Total & Negative & Total \\
\hline 24-hour monitoring & 7 & 2 & 5 & 10 & 24 & 23 & 47 \\
Multistage bicycle test & 12 & - & 6 & 7 & 25 & 22 & 47 \\
Single two-step test & 4 & - & 3 & 4 & 11 & 36 & 47 \\
\hline
\end{tabular}


TABLE 3 Details on ST-T changes in 21 patients with positive findings on both multistage bicycle test and 24-hour electrocardiographic monitoring

\begin{tabular}{|c|c|c|c|c|c|c|c|c|c|}
\hline \multirow[t]{2}{*}{$\begin{array}{l}\text { Case } \\
\text { No. }\end{array}$} & \multirow[t]{2}{*}{ Age } & \multirow[t]{2}{*}{ Sex } & \multirow{2}{*}{$\begin{array}{l}\text { Single } \\
\text { two-step } \\
\text { test }\end{array}$} & \multicolumn{2}{|c|}{$\begin{array}{l}\text { 24-hour electrocardio- } \\
\text { graphic monitoring }\end{array}$} & \multicolumn{4}{|c|}{ Multistage bicycle test } \\
\hline & & & & $\begin{array}{l}S T \\
\text { depression } \\
(\mathrm{mm})\end{array}$ & $\begin{array}{l}T \text { wave } \\
\text { inversion }\end{array}$ & $\begin{array}{l}S T \\
\text { depression } \\
(\mathrm{mm})\end{array}$ & $\begin{array}{l}T \text { wave } \\
\text { inversion }\end{array}$ & $\begin{array}{l}\text { Maximal } \\
\text { heart rate }\end{array}$ & Change in leads \\
\hline I & 46 & $\mathbf{F}$ & Positive & $\mathbf{I}$ & No & $I \cdot 5$ & No & 120 & $\mathrm{~V}_{5}$ \\
\hline 2 & 62 & $\mathbf{F}$ & Positive & I & Yes & 2 & No & 125 & $\mathrm{~V}_{5}$ \\
\hline 3 & 56 & $\mathrm{~F}$ & Negative & I & No & $1 \cdot 5$ & No & 135 & V5, II \\
\hline 4 & 55 & $\mathbf{M}$ & Positive & $1 \cdot 5$ & No & $1 \cdot 5$ & No & 100 & $\mathrm{~V}_{5}, \mathrm{II}$ \\
\hline 5 & 44 & $\mathbf{M}$ & Negative & I & No & I & No & 135 & $V_{5}, I, I I, a V L$ \\
\hline 6 & 43 & $\mathbf{M}$ & Negative & 2 & Yes & 2 & No & 140 & $V_{5}$, I, II \\
\hline 7 & 43 & M & Negative & No & Yes & I & Yes & 155 & V5, I, II \\
\hline 8 & $\begin{array}{l}43 \\
57\end{array}$ & $\mathbf{M}$ & Negative & 2 & Biphasic & 2 & No & 140 & II, III, aVF \\
\hline 9 & 45 & M & Negative & No & Yes & I & Yes & I 35 & V5, aVF \\
\hline 10 & 56 & $\mathrm{~F}$ & Positive & 2 & Yes & $1 \cdot 5$ & No & 140 & $V_{5}$ \\
\hline II & 45 & F & Positive & $\mathbf{I}$ & No & $1 \cdot 5$ & No & 120 & $V_{5}$ \\
\hline 12 & 54 & $M$ & Positive & I & Yes & 2 & Yes & 120 & V5, III, aVF \\
\hline 13 & 43 & $\mathrm{~F}$ & Positive & 2 & No & 2 & No & 105 & Vs \\
\hline 14 & 53 & $M$ & Positive & 3 & No & I & Yes & IIO & $V_{5}$ \\
\hline I5 & 51 & $\mathbf{M}$ & Negative & No & Yes & No & Yes & 150 & III, aVF \\
\hline 16 & 50 & $M$ & Positive & No & Yes & No & Yes & I 10 & V5 \\
\hline 17 & 48 & $M$ & Positive & $-2^{\star}$ & Biphasic & No & Yes & 100 & V5 \\
\hline 18 & 61 & F & Negative & 2 & Yes & I & No & 100 & $V_{5}$ \\
\hline 19 & 48 & M & Negative & 0.5 & Yes & I & Yes & I35 & $V_{5}$ \\
\hline 20 & 40 & $\mathrm{~F}$ & Negative & No & Yes & No & Yes & 145 & V5, III \\
\hline $2 I$ & 60 & $M$ & Negative & I & No & No & Yes & 125 & III, aVF \\
\hline
\end{tabular}

$\star$ ST elevation.

TABLE 4 Details on $S T-T$ changes in 4 patients with positive multistage test and negative 24-hour monitoring

\begin{tabular}{|c|c|c|c|c|c|c|c|c|}
\hline \multirow{2}{*}{$\begin{array}{l}\text { Case } \\
\text { No. }\end{array}$} & \multirow[t]{2}{*}{ Age } & \multirow[t]{2}{*}{ Sex } & \multirow{2}{*}{$\begin{array}{l}\text { Single } \\
\text { two-step } \\
\text { test }\end{array}$} & \multirow{2}{*}{$\begin{array}{l}\text { 24-hour electro- } \\
\text { cardiographic } \\
\text { monitoring }\end{array}$} & \multicolumn{3}{|c|}{ Multistage bicycle test } & \multirow[b]{2}{*}{$\begin{array}{l}\text { Change in } \\
\text { leads }\end{array}$} \\
\hline & & & & & $\begin{array}{l}S T \\
\text { depression } \\
(\mathrm{mm})\end{array}$ & $\begin{array}{l}T \\
\text { wave } \\
\text { inversion }\end{array}$ & $\begin{array}{l}\text { Maximal } \\
\text { heart rate }\end{array}$ & \\
\hline 22 & 44 & F & Negative & Negative & I & Yes & 145 & II, III, aVF \\
\hline 23 & 47 & $M$ & Negative & Negative & 1.5 & No & 135 & III, aVF \\
\hline 24 & $\begin{array}{l}41 \\
57\end{array}$ & $\mathbf{F}$ & Negative & Negative & No & Yes & II 5 & II, III, aVF \\
\hline 25 & 54 & $\mathrm{~F}$ & Positive & Negative & $1 \cdot 5$ & Yes & 130 & $\mathrm{~V}_{5}$ \\
\hline
\end{tabular}

TABLE 5 Details on $S T-T$ change in 3 patients with positive 24 -hour monitoring and negative multistage bicycle test

\begin{tabular}{lllllll}
\hline $\begin{array}{l}\text { Case } \\
\text { No. }\end{array}$ & Age & Sex & $\begin{array}{l}\text { Single } \\
\text { two-step } \\
\text { test }\end{array}$ & $\begin{array}{l}\text { 24-hour electrocardiographic } \\
\text { monitoring }\end{array}$ & Multistage bicycle test \\
\cline { 4 - 6 } & & & $\begin{array}{l}S T \text { depression } \\
(m m)\end{array}$ & $\begin{array}{l}\text { T wave } \\
\text { inversion }\end{array}$ & \\
\hline 26 & 40 & M & Negative & $-2^{\star}$ & No & $\begin{array}{l}\text { Negative } \\
\text { Yes }\end{array}$ \\
27 & 54 & F & Negative & I & Negative \\
No & 40 & M & Negative & I & Negative \\
\hline
\end{tabular}

* ST elevation. 
and 3 had ST-T changes on prolonged monitoring but were negative on the bicycle exercise tests (Table 5).

Changes in the ST segment without $T$ wave changes were slightly more prevalent on ergometry (12 patients) than on electrocardiographic monitoring (9 patients); isolated $T$ wave changes were found with a similar frequency by the two methods, while changes in both the ST segments and T waves were more frequent on monitoring (Table $I$ ). In only one patient were the findings negative on monitoring but positive on both the Master's test and bicycle ergometry. In another patient, with negative exercise tests, there was a transient elevation of the ST segment during 24-hour monitoring.

\section{Discussion}

The importance of the exercise tests in the diagnosis of asymptomatic and/or atypical ischaemic heart disease has been well established in the past decade (Mattingly, I962; Robb and Marks, 1967). In recent years, multistage exercise bicycle or treadmill tests have taken the place of the Master's two-step test. These tests are more strenuous and the amount of exercise performed is better controlled. The sensitivity of the maximal exercise capacity test was found to be nine times greater than that of the double Master two-step test in a recent report by Doan et al. (1965). Sheffield, Holt, and Reeves (1965), in a study on patients with ischaemic heart disease, reported 20 to 25 per cent more positive results from the maximal exercise test than from the double twostep test. Similarly, Bellet and Roman (1967) found that the maximal treadmill exercise test increased the yield of positive results by 12 per cent, as compared to the double two-step test.

Continuous 24-hour electrocardiographic monitoring by the Holter system has been used mainly for detection of cardiac arrhythmias and there are only a few descriptions of ST-T segment changes during monitoring (Norland and Semler, 1964; Aronow et al., 1972; Golding et al., 1973). This is possibly due to the report by Hinkle et al. (1967) who raised doubts concerning the reliability of the Holter system in recording ST-T changes. However, the new model of the Electrocardiocorder has been recently found to be reliable in this respect and no artefacts due to the recording system were detected when recording either normal or pathological patterns (Stern and Tzivoni, 1972). Moreover, in a control group of 42 normal subjects with no clinical or electrocardiographic evidence of cardiovașcular disease, no ST-T changes were found during the 24-hour monitoring period (Stern and Tzivoni, I973), making highly improbable the possibility of false positive results.
The present study on 47 patients with suspected ischaemic heart disease confirms that the multistage ergometry test is much more sensitive in detecting ischaemic ST-T changes than the 'single Master's test'. Moreover, both ergometry and the 24-hour electrocardiographic monitoring disclose ST-T changes in a relatively high percentage of the cases, and a good correlation was found between the results obtained by these two methods. A discrepancy was found in only 7 patients: in 4 of them there were ST-T changes in ergometry but not during monitoring and this may have been due to the fact that only one chest lead is recorded during monitoring so that changes occurring only in the limb leads may escape detection; in fact, in 3 of these 4 patients the changes on ergometry were confined to the limb leads. However, 2 other patients with ST-T changes confined to the limb leads during ergometry revealed similar changes on monitoring. In I of the 3 patients with positive findings on monitoring only, but negative exercise tests, the discrepancy was explained by the fact that the ST elevation seen on monitoring was most probably the phenomena of 'Prinzmetal's angina', appearing at rest and therefore not detectable by exercise tests (Hilal and Massumi, 1967).

There are no generally accepted criteria for the interpretation of ST-T changes during or after quantitated exercise tests and even less so for the changes occurring during effort or under the influence of stress and emotion. The appearance of ST depression of the 'segmental' type after exercise tests is, however, regarded as pathognomonic of ischaemic heart disease. The degree of ischaemic ST depression indicates the degree of coronary insufficiency and prognosis (Master and Geller, 1969). We believe that the appearance of this change during ambulatory monitoring under unrestricted daily activities is similarly indicative of coronary disease, especially if seen in patients over the age of 40 with praecordial symptoms. This assumption is supported by the good correlation found between this and the ergometric test, with respect to the detection of ST depression. The diagnostic value of $T$ wave inversion in the course of exercise tests is even less clearly defined (Mattingly, 1962), and we only regarded deep inversion as positive, both for the exercise test and for the monitoring. In this respect also there was good correlation between the two tests, as in 3 of 5 patients with isolated $T$ wave inversion on monitoring similar changes were also detected by the exercise test.

The fairly good correlation between the findings on 24-hour ambulatory monitoring under dynamic conditions and in the multistage ergometric test 
indicates the reliability of the former method in detecting early ST-T changes in patients with atypical praecordial symptoms. Moreover, it is our experience that the two tests complement one another, and that the yield of detection of positive cases can be increased by performing both tests in patients with suspected ischaemic heart disease.

The authors thank Mrs. Batia Glassman for her technical assistance.

\section{References}

Aronow, W. S., Harris, C. N., Isbel, M. W., Rokaw, S. N., and Imparato, B. (1972). Effect of freeway travel on angina pectoris. Annals of Internal Medicine, 77, 669.

Bellet, S., and Roman, L. (1967). Comparison of the double two-step test and the maximal exercise treadmill test: studies in coronary-prone subjects. Circulation, 36, 238.

Corday, E., Bazika, V., Lang, T. W., Pappelbaum, S., Gold, H., and Bernstein, H. (1965). Detection of phantom arrhythmias and evanescent electrocardiographic abnormalities. Use of prolonged direct electrocardiocording. Fournal of the American Medical Association, 193, 417.

Doan, A. E., Peterson, D. R., Blackmon, J. R., and Bruce, R. A. (1965). Myocardial ischemia after maximal exercise in healthy men: a method for detecting potential coronary heart disease ? American Heart fournal, 69, II.

Gilson, J. S., Holter, N. J., and Glasscock, W. R. (1964). Clinical observations using the Electrocardiocorder AVSEP continuous electrocardiographic system; tentative standards and typical patterns. American fournal of Cardiology, 14, 204.

Golding, B., Wolf, E., Tzivoni, D., and Stern, S. (1973). Transient S-T elevation detected by 24 -hour ECG monitoring during normal daily activity. American Heart Fournal, 86, 501.

Hilal, H., and Massumi, R. (1967). Variant angina pectoris. American fournal of Cardiology, 19, 607.

Hinkle, L. E., Meyer, J., Stevens, M., and Carver, S. T. (1967). Tape recordings of the E.C.G. of active men: limitations and advantages of the Holter-Avionics instruments. Circulation, 36, 752.
König, K., and Messin, R. (1970). Methods of evaluation of the physical capacity. Acta Cardiologica, Suppl., 14, 30.

Master, A. M. (1953). The 'two-step' exercise electrocardiogram. Its use in heart disease, including valvular heart disease of adults. Bulletin of the St. Francis Hospital and Sanatorium, 10, I.

Master, A. M., and Geller, A. J. (1969). The extent of completely asymptomatic coronary artery disease. American Fournal of Cardiology, 23, 173.

Master, A. M., and Rosenfeld, J. (I967). Two-step exercise test: current status after twenty-five years. Modern Concepts of Cardiovascular Diseases, 36, 19.

Mattingly, T. W. (1962). The postexercise electrocardiogram: its value in the diagnosis and prognosis of coronary arterial disease. American fournal of Cardiology, 9, 395.

Norland, C. C., and Semler, H. J. (1964). Angina pectoris and arrhythmias documented by cardiac telemetry. Fournal of the American Medical Association, 190, II5.

Robb, G. P., and Marks, H. H. (1967). Postexercise electrocardiogram in arteriosclerotic heart disease: its value in diagnosis and prognosis. Fournal of the American Medical Association, $200,918$.

Sheffield, L. T., Holt, J. H., and Reeves, T. J. (1965). Exercise graded by heart rate in electrocardiographic testing for angina pectoris. Circulation, 32, 622 .

Stern, S., Ben-Shachar, G., Tzivoni, D., and Braun, K. (I970). Detection of transient arrhythmias by continuous long-term recording of electrocardiograms of active subjects. Israel fournal of Medical Sciences, 6, 103.

Stern, S., and Tzivoni, D. (1972). The reliability of the Holter-Avionics system in reproducing the ST-T segment. American Heart fournal, 84, 427.

Stern, S., and Tzivoni, D. (1973). Dynamic changes in the ST-T segment during sleep in ischemic heart disease. American fournal of Cardiology, 32, 17.

Tzivoni, D., and Stern, S. (1972). Improved method of operating the Holter-Avionics ECG recording system. American Heart fournal, 83, 846.

Requests for reprints to Dr. Shlomo Stern, Department of Cardiology, Hadassah University Hospital, P.O.B. 499, Jerusalem, Israel. 